\title{
O Cenário Profissional e os Conhecimentos acerca da Propriedade Intelectual, da Transferência Tecnológica e da Inovação de Manaus/AM
}

\author{
Professional Scenario and Knowledge About Intellectual Property, \\ Technological Transfer and Innovation of Manaus/AM
}

\author{
Desirée Emelly Gomes Nascimento ${ }^{1}$ \\ Acursio Ypiranga Benevides Junior ${ }^{1,2,3,5}$ \\ Daniela Azevedo da Silva ${ }^{1}$ \\ Érika Santos Gomes ${ }^{1,4}$ \\ Rosa Maria Nascimento dos Santos ${ }^{1}$ \\ Raimundo Correa de Oliveira ${ }^{1}$ \\ ${ }^{1}$ Universidade do Estado do Amazonas, Manaus, AM, Brasil \\ ${ }^{2}$ Universidade Federal do Amazonas, Manaus, AM, Brasil \\ ${ }^{3}$ Centro Universitário do Norte, Manaus, AM, Brasil \\ ${ }^{4}$ Instituto Federal do Amazonas, Presidente Figueiredo, AM, Brasil \\ 5Universidade Estácio de Sá, Manaus, AM, Brasil
}

\begin{abstract}
Resumo
O Estado do Amazonas e os demais estados da Região Norte compõem a única região brasileira que não transferiu tecnologia formalmente nos anos de 2013 a 2016, mediante contratos de propriedade intelectual, pelas vias de instituições de ciência e tecnologia (ICTs), nela localizadas. No cenário amazonense, os profissionais que atuam nas ICTs estão aptos ao exercício da transferência tecnológica, pertinente à propriedade intelectual e à inovação? Este artigo propõe identificar a realidade fática do cenário profissional e os conhecimentos acerca da propriedade intelectual, transferência tecnológica e inovação. Para tal, utilizar-se-á de pesquisa de opinião obtida por meio de questionário com profissionais das empresas e ICTs da cidade de Manaus. O resultado apresenta que o cenário profissional possui base para lidar com a questão da propriedade intelectual e transferência tecnológica.
\end{abstract}

Palavras-chave: Amazônia. Propriedade Intelectual. Transferência Tecnológica.

\begin{abstract}
The State of Amazonas, together with the other states in the northern region, make up the only Brazilian region that did not formally transfer technology in the years 2013 to 2016, through intellectual property contracts, through science and technology institutions (ICTs), in it located. Is the Amazon scenario of the professionals working in the ICTs apt to exercise the technology transfer relevant to intellectual property and innovation? This article proposes to identify the factual reality of the professional scene and the knowledge about intellectual property, technology transfer and innovation. For this purpose, a opinion survey research will be used with professionals from the companies and ICTs of the city of Manaus. The result shows that the professional scenario has a basis to deal with the issue of intellectual property and technology transfer.
\end{abstract}

Keywords: Amazon. Intellectual Property. Technological Transfer.

Área Tecnológica: Propriedade Intelectual. Transferência de Tecnologia. Inovação. 


\section{Introdução}

O Estado do Amazonas, maior estado do país em extensão territorial, com 1.559.148,890 $\mathrm{km}^{2}$ (IBGE, 2017), concluiu o ano de 2018 com queda na produção industrial em 3,5\% (IBGE, 2018), cenário que expõe o Polo Industrial de Manaus (PIM), cidade considerada a detentora do sétimo PIB municipal entre os maiores do cenário nacional, atrás apenas de São Paulo, Rio de Janeiro, Brasília, Belo Horizonte, Curitiba e Porto Alegre (CALEIRO, 2017), o que apresenta a relevância da região, não apenas para a Região Norte do país, para a economia brasileira como um todo, "com participação de 1,12\% da produção total" (CALEIRO, 2017).

Junto com Acre, Rondônia, Roraima, Pará, Amapá e Tocantins, o Amazonas compõe a única região brasileira que não transferiu tecnologia formalmente nos anos de 2013 a 2016, conforme apontam os dados do Formulário para Informações sobre a Política de Propriedade Intelectual das Instituições Científicas, Tecnológicas e de Inovação (FORMICT) do Brasil (MINISTÉRIO DA CIÊNCIA, TECNOLOGIA, 2016; 2017, MINISTÉRIO DA CIÊNCIA, 2014; 2015).

Essa transferência formal de tecnologia é, via de regra, realizada mediante contratos de propriedade intelectual pelas Instituições de Ciência e Tecnologia (ICT).

Como o Amazonas é um elemento estratégico para o desenvolvimento nacional em virtude de seu modelo de desenvolvimento econômico da Zona Franca de Manaus (ZFM), surge o questionamento: o cenário amazonense dos profissionais que atuam nas ICTs está apto ao exercício da transferência tecnológica pertinente à propriedade intelectual e à inovação? Essa é a problemática que guia este artigo.

Para a Organização para Cooperação e Desenvolvimento Econômico (OCDE), as inovações advêm de atividades baseadas no conhecimento que envolve a aplicação prática de informações e de conhecimentos existentes ou recém-desenvolvidos, considerando informações, como os dados organizados passíveis de transferência entre organizações, e conhecimento, como o entendimento das informações e a capacidade de usá-las em propósitos distintos (OECD/ EUROSTAT, 2018).

A transferência das informações e do conhecimento relacionado a elas, de forma que possibilite sua utilização para gerar inovação, adentra o campo da propriedade intelectual e da transferência tecnológica. As atividades relacionadas à propriedade intelectual incluem a proteção ou a exploração do conhecimento, geralmente criadas por meio de $\mathrm{P} \& \mathrm{D}$, desenvolvimento de software e engenharia, design e outros trabalhos criativos (OECD/EUROSTAT, 2018). Porém, ressalta-se que isso não se limita ao campo da criação.

Nesse contexto, também são consideradas atividades de PI as que incluem os trabalhos jurídicos e administrativos de solicitar, registrar, documentar, gerenciar, licenciar, comercializar e fazer valer os direitos de propriedade intelectual (OECD/EUROSTAT, 2018), geralmente, por meios de contrato de transferência tecnológica.

A transferência tecnológica são atividades de organizações relacionadas com transação de direitos, por exemplo, por meio de licenças ou mesmo a compra definitiva dos direitos alienáveis relacionados à propriedade intelectual (OECD/EUROSTAT, 2018), que pode incluir patentes de invenção, patentes de modelos de utilidades, desenhos industriais, marcas registradas, indicações geográficas, direitos autorais e conexos, programas de computador, circuitos integrados, 
cultivar e, ainda, questões pertinentes ao conhecimento de comunidades tradicionais e acesso ao patrimônio genético (INPI; CNI, 2010).

Como visto, os conteúdos de propriedade intelectual, transferência tecnológica e inovação estão correlacionados e essa conexão que é tema pertinente aos interesses do Polo Industrial de Manaus, centro beneficiário da Zona Franca, regulada inicialmente pelo Decreto-Lei n. 288, de 1967.

Posteriormente, a Constituição da República de 1988, em seu artigo 40 do Ato das Disposições Constitucionais Transitórias (ADCT), assegurou a manutenção da política: "É mantida a Zona Franca de Manaus, com suas características de área livre de comércio, de exportação e importação, e de incentivos fiscais, pelo prazo de vinte e cinco anos, a partir da promulgação da Constituição." (BRASIL, 1988, art. 40)

O prazo final de vigência dos efeitos da norma constitucional foi alterado duas vezes. A primeira atualização veio com a Emenda Constitucional n. 42, de 2003, acrescentando o artigo 92 do ADCT: "São acrescidos dez anos ao prazo fixado no art. 40 deste Ato das Disposições Constitucionais Transitórias". Em 2014, o Congresso Nacional, promulgou a Emenda Constitucional n. 83, que, em seu artigo $1^{\circ}$ assegura: "O Ato das Disposições Constitucionais Transitórias passa a vigorar acrescido do seguinte artigo 92-A: Art. 92-A. São acrescidos 50 (cinquenta) anos ao prazo fixado pelo art. 92 deste Ato das Disposições Constitucionais Transitórias".

Nesse sentido, a política nacional de incentivo e de integração regional e econômica da Zona Franca de Manaus, então, possui o prazo de duração até 2073, como elemento estratégico de desenvolvimento nacional. Cenário este em que os setores tecnológicos possuem a oportunidade de maior desenvolvimento, e o campo da propriedade intelectual e da transferência tecnológica é um dos indicadores desse desenvolvimento.

No intuito de melhor entender a problemática levantada, este artigo propõe identificar a realidade fática do cenário profissional e os conhecimentos acerca da propriedade intelectual, da transferência tecnológica e da inovação. Para tal, foi aplicada uma pesquisa por meio de questionário preparado para este fim em profissionais das empresas e ICTs da cidade de Manaus.

\section{Metodologia}

A pesquisa em apreço fundamentou-se no caráter bibliográfico e descritivo e pretende compreender o cenário profissional e o conhecimento sobre a Propriedade Intelectual, a Transferência de Tecnologia e a Inovação na cidade de Manaus, considerando a ZFM, a qual possui mais de 600 indústrias de alta tecnologia, sendo que as que produzem bens e serviços de informática possuem a obrigatoriedade de aplicar no mínimo $5 \%$ do seu faturamento bruto no mercado interno, em atividades de Pesquisa e Desenvolvimento (P\&D) na Amazônia Ocidental (BRASIL, 1991). Para o melhor entendimento sobre a Propriedade Intelectual, a Transferência de Tecnologia e a Inovação no âmbito da Amazônia Ocidental, realizou-se um levantamento bibliográfico por meio da análise documental em leis, relatórios e em outros documentos públicos.

Para a coleta dos dados foi elaborado um survey na plataforma Google Forms contendo 13 questões em cada seção, sendo elas: "Atua como profissional/bolsista de ICT privada" e "Atua como profissional/bolsista de ICT pública (Autarquia/Fundação Federal, Estadual, Municipal Institutos, Universidades, Escolas) ou em entidades do Sistema S (Senai, Senac, Sebrae, Senat, 
Senai)". A pesquisa foi aplicada nos dias 27, 28 e 29 de novembro de 2018 na I Feira do Polo Digital de Manaus.

Nos dias 27 a 29 de novembro de 2018 foi realizado na capital do Estado do Amazonas a I Feira do Polo Digital de Manaus com o tema "Manaus tem digital", promovido pelo Conselho de Desenvolvimento Econômico, Sustentável e Estratégico (CODESE Manaus) e sua Câmara de Tecnologia e Inovação, com patrocínio do Instituto de Desenvolvimento para a Informática da Amazônia (SIDIA). A feira expôs iniciativas locais e contou com a participação de convidados expoentes em suas áreas no Brasil e no mundo. Os objetivos do evento foram: discutir os incentivos para a indústria 4.0 do PIM; aplicar os recursos de P\&D; e demonstrar diversas soluções inovadoras de tecnologia da informação, por meio de exposição de startups, empresas de produtos/serviços de tecnologia da informação, ICTs públicos e privados, além de instituições de ensino superior. Tendo em vista tal evento e a integração do Mestrado Profissional em Propriedade Intelectual e Transferência de Tecnologia para a Inovação (PROFNIT) em Manaus, teve-se a oportunidade de participar do referido evento como expositores com o propósito de divulgar o Programa de Mestrado por meio de folders, além de realizar o networking com a aplicação do questionário elaborado.

Figura 1 - Estande do Profnit/AM na I Feira do Polo Digital

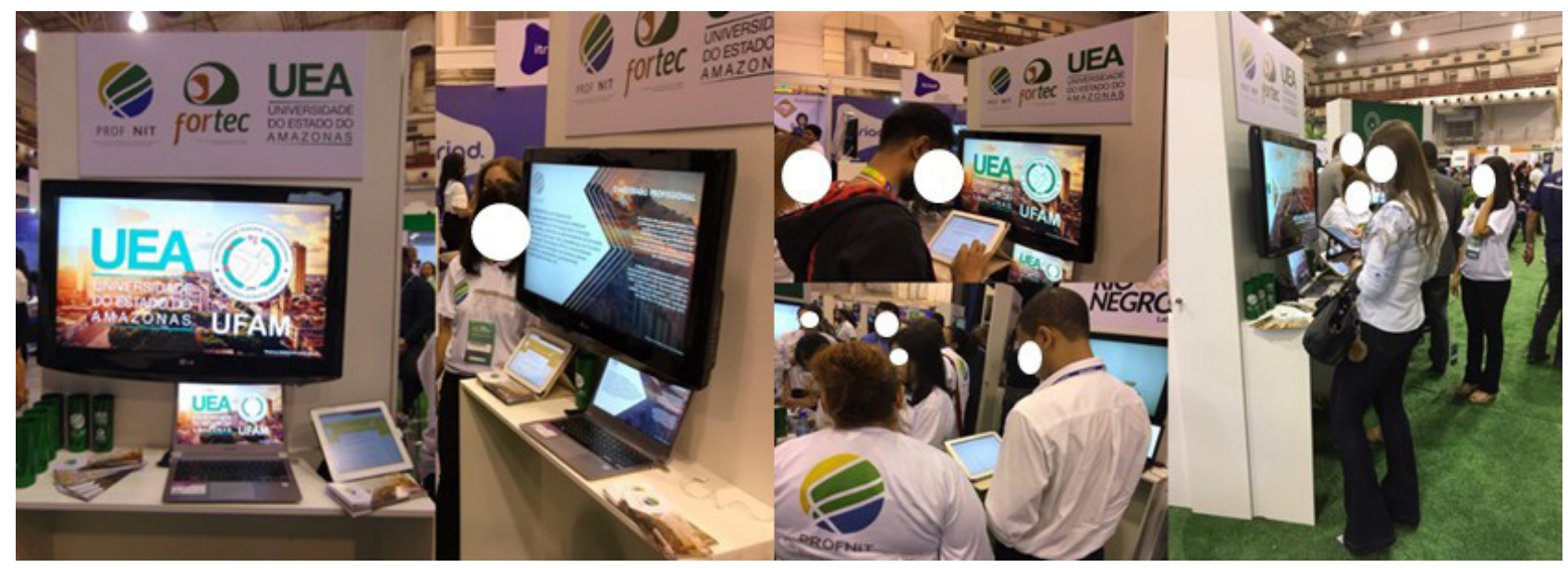

Fonte: Arquivo Profnit/UEA (2018)

A Figura 1 também apresenta a realização de um networking com a aplicação do questionário elaborado. A organização do networking foi realizada em conjunto com as turmas do Profnit da Universidade do Estado do Amazonas (UEA) e da Universidade Federal do Amazonas (UFAM). Houve a participação das coordenações de ambas as universidades e de professores, como o Dr. Raimundo Correa de Oliveira (UEA), o Dr. Dalton Vilela (UFAM), a Dra. Rosa Maria Nascimento dos Santos (UEA). Além da participação do professor Dr. Josealdo Tonholo, Pró-Reitor do Fórum Nacional de Gestores de Inovação e Transferência de Tecnologia (FORTEC). 
Figura 2 - Equipe Profnit UEA e UFAM

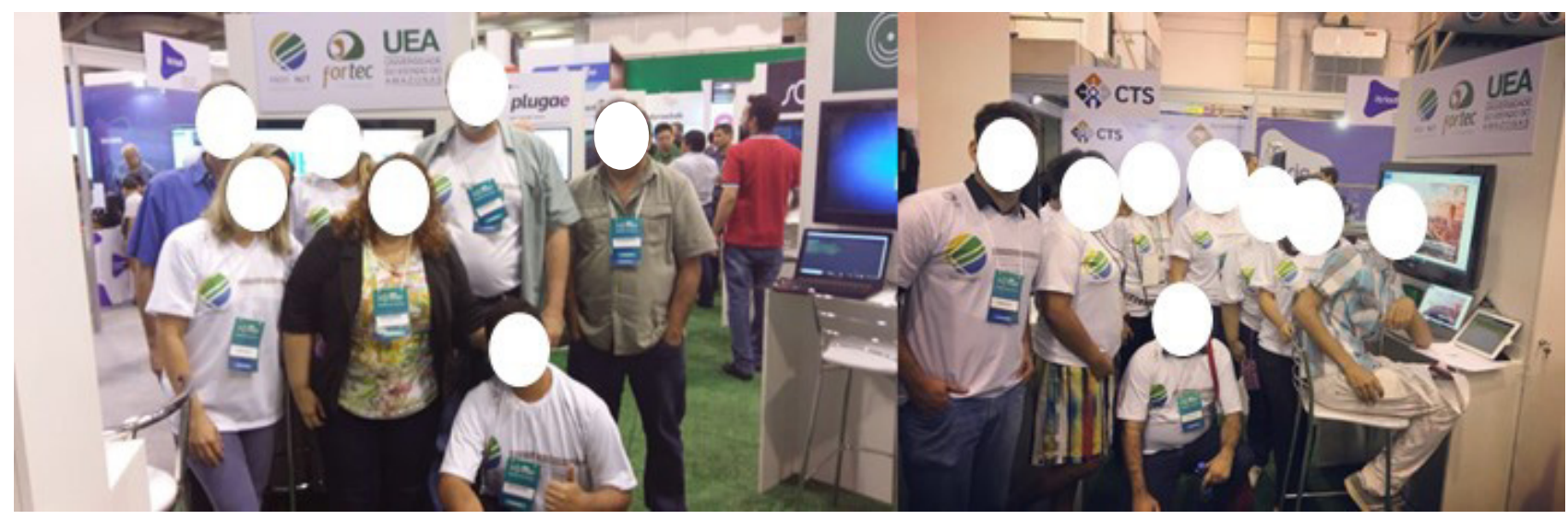

Fonte: Arquivo Profnit/UEA (2018)

De maneira geral, foram obtidas 50 respostas como resultado do questionário, sendo $40 \%$ de profissionais de ICTs privadas, considerando funcionários e bolsistas, e $60 \%$ de profissionais e bolsistas de ICTs públicas e do terceiro setor.

\section{Resultados e Discussão}

Os resultados da pesquisa foram expostos com os dados do perfil profissional e do perfil da instituição para serem discutidos e interpretados coletivamente e foram sistematizados em: 1) Perfil Profissional e 2) Perfil Institucional.

\subsection{Perfil Profissional}

Sobre os profissionais, tanto no setor público e no terceiro setor quanto no setor privado, nota-se que a maior faixa de escolaridade é formada pelos profissionais com nível superior, técnico ou tecnólogo; porém, se considerar o montante de profissionais com pós-graduação stricto sensu, percebe-se a superioridade numérica do setor público e terceiro setor, computando um total de $50 \%$ dos respondentes com diplomas de mestres e de doutores, conforme pode ser visualizado no Gráfico 1.

Gráfico 1 - Nível de escolaridade dos profissionais de ICTs respondentes da pesquisa Setor Privado
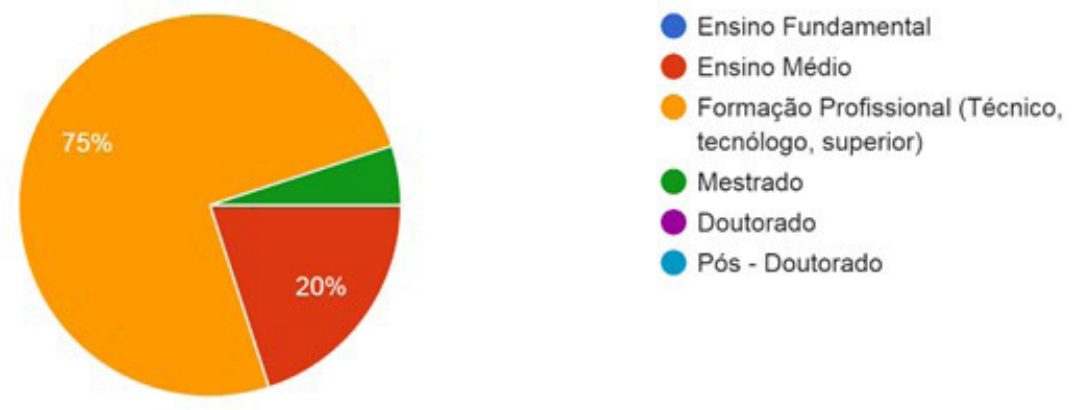


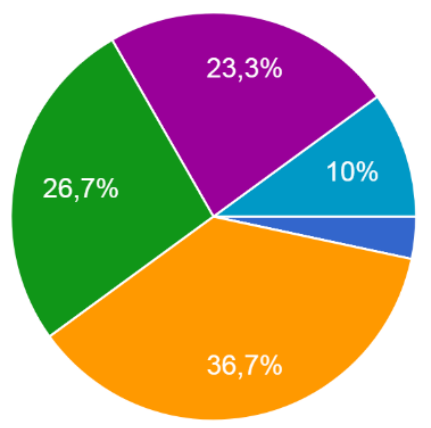

Ensino Fundamental

Ensino Médio

Formação Profissional (Técnico, tecnólogo, superior)

Mestrado

Doutorado

Pós - Doutorado

Fonte: Elaborado pelos autores deste artigo (2018)

A representatividade de profissionais com diplomas stricto sensu no setor privado é de apenas $5 \%$ dos participantes da pesquisa, nesse caso, de profissionais do setor privado com titulação de mestre. Nos dados não constam respondentes com diplomas de doutorado nas ICTs do Setor Privado que estavam participando do evento da I Feira do Polo Digital de Manaus.

Sobre essa análise do perfil profissional dos respondentes da pesquisa, preliminarmente, o resultado aponta uma necessidade de formação profissional mais avançada para ambos os setores, em especial para o setor privado. No caso do setor público e terceiro setor, apesar de constar com metade dos respondentes com formação stricto sensu, o resultado não pode ser considerado o ideal, mas representa um avanço comparado às ICTs do setor privado.

No que concerne à identificação da atuação dos profissionais nas áreas dentro das ICTs, as perguntas foram direcionadas para identificar as seguintes áreas de atuação profissional: Setor de pesquisas, análise e ciência; Criação, desenvolvimento e testes de produtos, processos e serviços (Design, Programação, Engenharia); Comunicação, Marketing e Vendas; Setores administrativos, jurídicos e de Recursos Humanos.

Gráfico 2 - Áreas de atuação dos profissionais respondentes nas ICTs em que trabalham

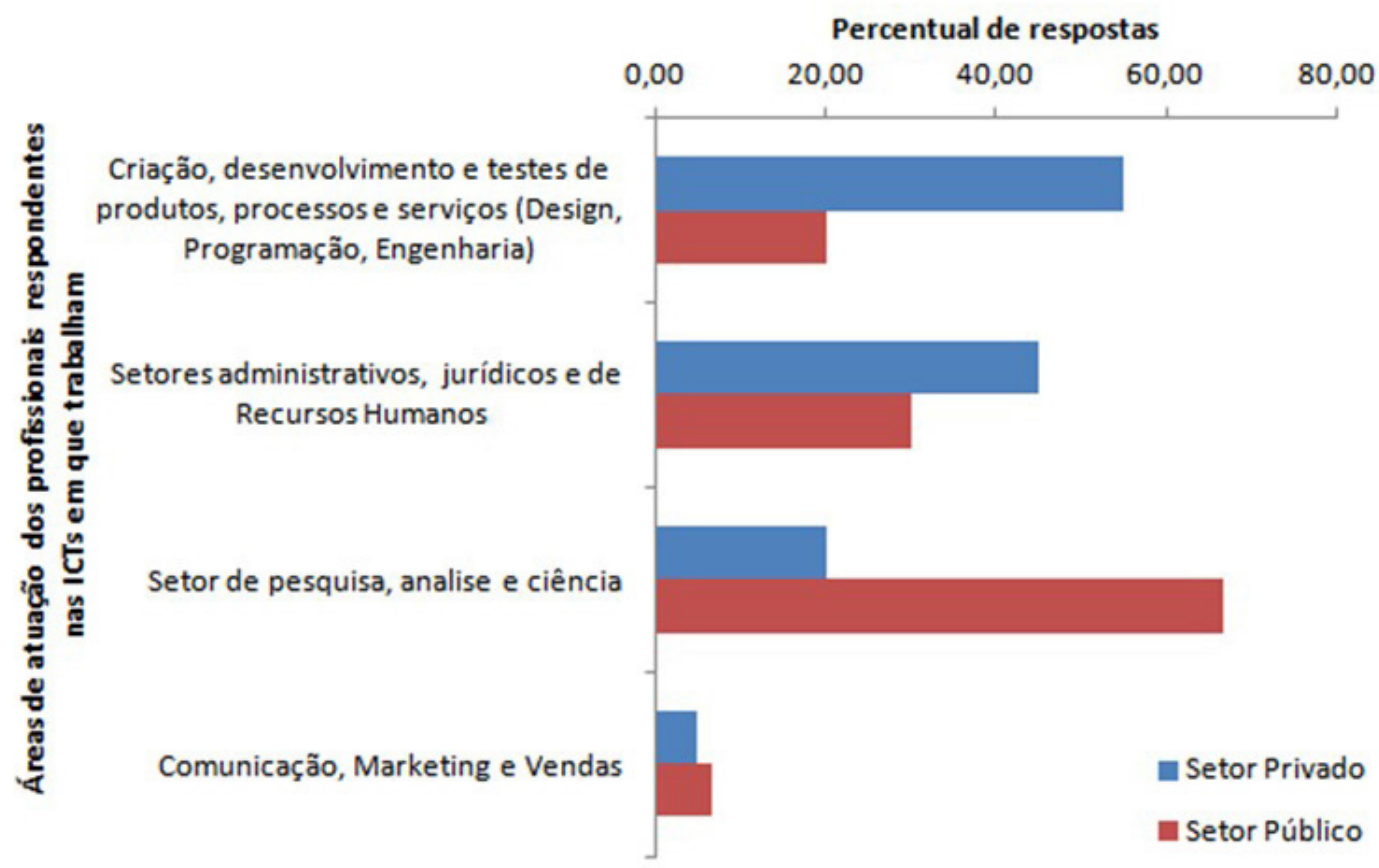

Fonte: Elaborado pelos autores deste artigo (2018) 
Os dados expõem resultados diferentes, dependendo se a ICT é de setor público e terceiro setor ou setor privado. No caso do setor privado, o grande expoente está na Criação, desenvolvimento e testes de produtos, processos e serviços (Design, Programação, Engenharia).

Já no setor público e terceiro setor, os dados apresentam maior incidência de profissionais do Setor de pesquisas, análise e ciência. Em segundo lugar como expoente, em ambos os setores, encontram-se profissionais dos Setores administrativos, jurídicos e de Recursos Humanos.

A tendência é apresentar a aderência para prestação de serviços na área de Criação, desenvolvimento e testes de produtos, processos e serviços (Design, Programação, Engenharia) dos profissionais do setor privado, bem como a de Setor de pesquisas, análise e ciência, para os profissionais do setor público e do terceiro setor.

Esse mapeamento evidencia uma percepção já sentida empiricamente nas ICTs da cidade de Manaus, na qual o ramo público é mais vinculado à educação e à pesquisa, e o privado, à prestação de serviços. Sobre a relação dos profissionais respondentes e o tema da propriedade intelectual, apenas $15 \%$ dos dados referentes ao setor privado apresentam profissionais que não conhecem o tema de PI e não pretendem conhecer, e 10\%, apesar de não conhecerem, possuem interesse, totalizando um total de $25 \%$ de profissionais sem conhecimento sobre $\mathrm{PI}$; do lado do setor público e terceiro setor, não há profissionais sem interesse em conhecer o tema da PI, e os profissionais respondentes, que, apesar de não terem conhecimento, pretendem conhecer, somam $26,7 \%$.

Os dados mostram uma aproximação do percentual entre profissionais sem acesso aos temas de PI em ambos os setores.

Gráfico 3 - O profissional, a propriedade intelectual e a transferência tecnológica Setor Privado

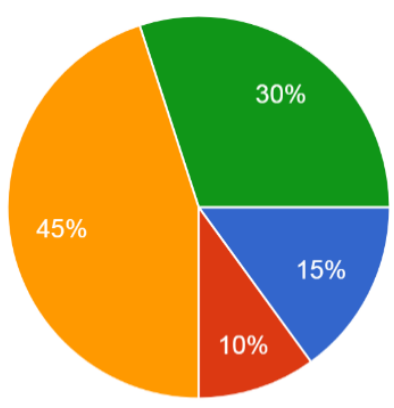

Não conheço o tema de PI e não pretendo conhecer

Não conheço o tema de PI, mas pretendo conhecer

Conheço o tema de PI e acredito não possuir relação com as atividades da empresa

Conheço o tema de PI e acredito possuir relação com as atividades da empresa

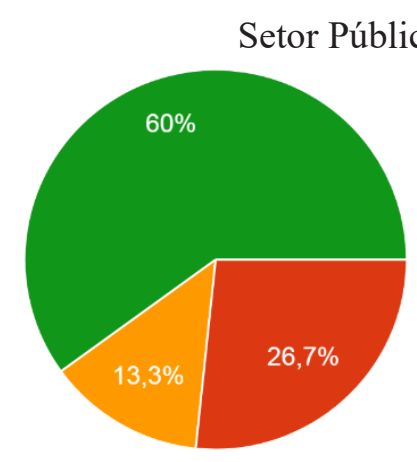
Não conheço o tema de PI e não pretendo conhecer
Não conheço o tema de PI, mas pretendo conhecer
Conheço o tema de PI e acredito não possuir relação com as atividades da empresa
Conheço o tema de PI e acredito possuir relação com as atividades da empresa

Fonte: Elaborado pelos autores deste artigo (2018)

Quando se trata de identificar se o tema de PI tem relação com a atividade da ICT, a pesquisa mostra que, para $45 \%$ dos respondentes de ICTs privadas que possuem conhecimento sobre 
PI, o tema não possui relação com as atividades da empresa, restando um percentual de $30 \%$ para aqueles que acreditam que as atividades das ICTs em que atuam possuem relação com o tema de PI; o cenário muda para os respondentes de ICTs públicas e do terceiro setor, já que $60 \%$ dos respondentes consideram que a atividade de ICT possui relação com o tema de PI.

O fato de $45 \%$ dos respondentes de ICTs privadas responderam que o tema de PI não possui relação com as atividades da empresa ICT é curioso, primeiro porque o Gráfico 2 (Áreas de atuação dos profissionais respondentes nas ICTs em que trabalham) mostra que o maior percentual é de respondentes das áreas de Criação, desenvolvimento e testes de produtos, processos e serviços (Design, Programação, Engenharia), atividade esta que, em tese, possui relação com o tema de $\mathrm{PI}$.

Essa informação pode ser uma indicação do baixo conhecimento sobre abrangência materiais de propriedade intelectual; porém, a certeza científica para essa informação não existe, devido ao não aprofundamento do método e do questionário.

No tocante ao tema de Transferência Tecnológica (TT), os profissionais foram questionados sobre a relação dos ICTs com contratos de transferência tecnológica. Os dados estão expostos no Gráfico 4.

Gráfico 4 - Sobre os profissionais respondentes e a relação com a transferência tecnológica

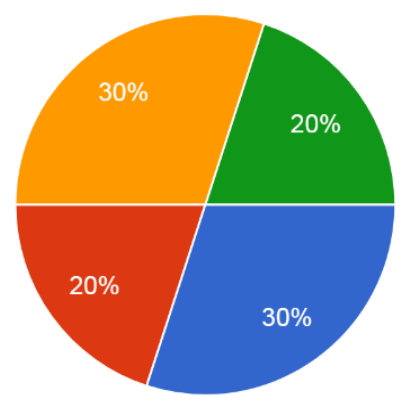

$$
\text { Setor Privado }
$$

Não há conhecimentos técnicos jurídicos sobre contratos de transferência tecnológica na empresa e não se transfere e nem pretende-se transferir tecnologia no meu local de trabalho;

- Não há conhecimentos técnicos jurídicos sobre contratos de transferência tecnológica na empresa, mas transfere-se/pretende-se transferir tecnologia no meu local de trabalho;

- Há conhecimentos técnicos jurídicos sobre contratos de transferência tecnológica na empresa e transfere-se/pretende-se transferir tecnologia com suporte técnico de profissionais de dentro da empresa;

- Há conhecimentos técnicos jurídicos sobre contratos de transferência tecnológica na empresa e transfere-se/pretende-se transferir tecnologia com suporte técnico de profissionais externos à empresa.

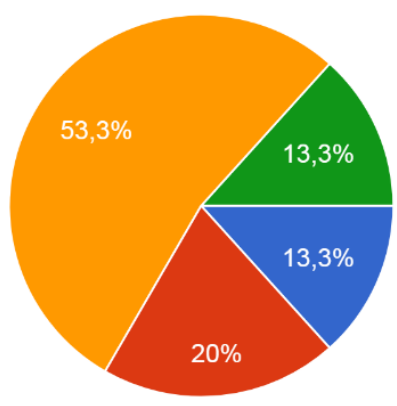

Setor Público e Terceiro Setor

Não há conhecimentos técnicos jurídicos sobre contratos de transferência tecnológica na empresa e não se transfere e nem pretende-se transferir tecnologia no meu local de trabalho;

- Não há conhecimentos técnicos jurídicos sobre contratos de transferência tecnológica na empresa, mas transfere-se/pretende-se transferir tecnologia no meu local de trabalho;

Há conhecimentos técnicos jurídicos sobre contratos de transferência tecnológica na empresa e transfere-se/pretende-se transferir tecnologia com suporte técnico de profissionais de dentro da empresa:

- Há conhecimentos técnicos jurídicos sobre contratos de transferência tecnológica na empresa e transfere-se/pretende-se transferir tecnologia com suporte técnico de profissionais externos à empresa.

Fonte: Elaborado pelos autores deste artigo (2018)

Percebe-se que, no setor público e no terceiro setor, o maior percentual dos profissionais respondentes é dotado de conhecimentos técnicos jurídicos sobre contratos de transferência tecnológica na ICT em que atuam e que se transfere/se pretende transferir tecnologia, somando total de $66,6 \%$ (53,3\% e 13,3\%). Ocorre que, para 53,3\%, a pretensão é a utilização de suporte técnico de profissionais de dentro da instituição e, para outros 13,3\%, com suporte externo à ICT; quando se fala em profissionais de ICTs privadas, esse percentual cai para $50 \%$ dos respondentes. 
Para 20\% de ambos os setores, apesar de ausência de conhecimento, há a pretensão de transferir. E, sobre os profissionais que responderam que não há conhecimento nem transferência tecnológica ou sua pretensão, para o setor público e terceiro setor, o número é de 13,3\%, sendo de $30 \%$ para o setor privado.

\subsection{Perfil Institucional}

Na oportunidade de recolher dados dos profissionais participantes da I Feira do Polo Digital da Cidade de Manaus, também foi possível catalogar informações referentes ao perfil institucional das ICTs em que eles atuam.

Das 50 pessoas entrevistadas, 20 atuavam em ICTs privadas e 30 em ICTs públicas. Os respondentes de ICTs privadas atuaram em 14 segmentos, sendo os cinco principais segmentos de suas ICTs: Mobile (40,00\%), Web App (30,00\%), Hardware (30,00\%), Educação (25,00\%) e Games (25,00\%).

Os respondentes de ICTs públicas listaram sua atuação em 18 segmentos, sendo o mais expressivo o segmento de Educação (76,67\%), seguido de Meio Ambiente (16,67\%), Mobile, Saúde, Finanças, TICs e Comunicação, todos com 13,33\%. A distribuição dos percentuais em cada segmento pode ser observada no Gráfico 5.

Gráfico 5 - Área de atuação dos ICTs dos respondentes da pesquisa

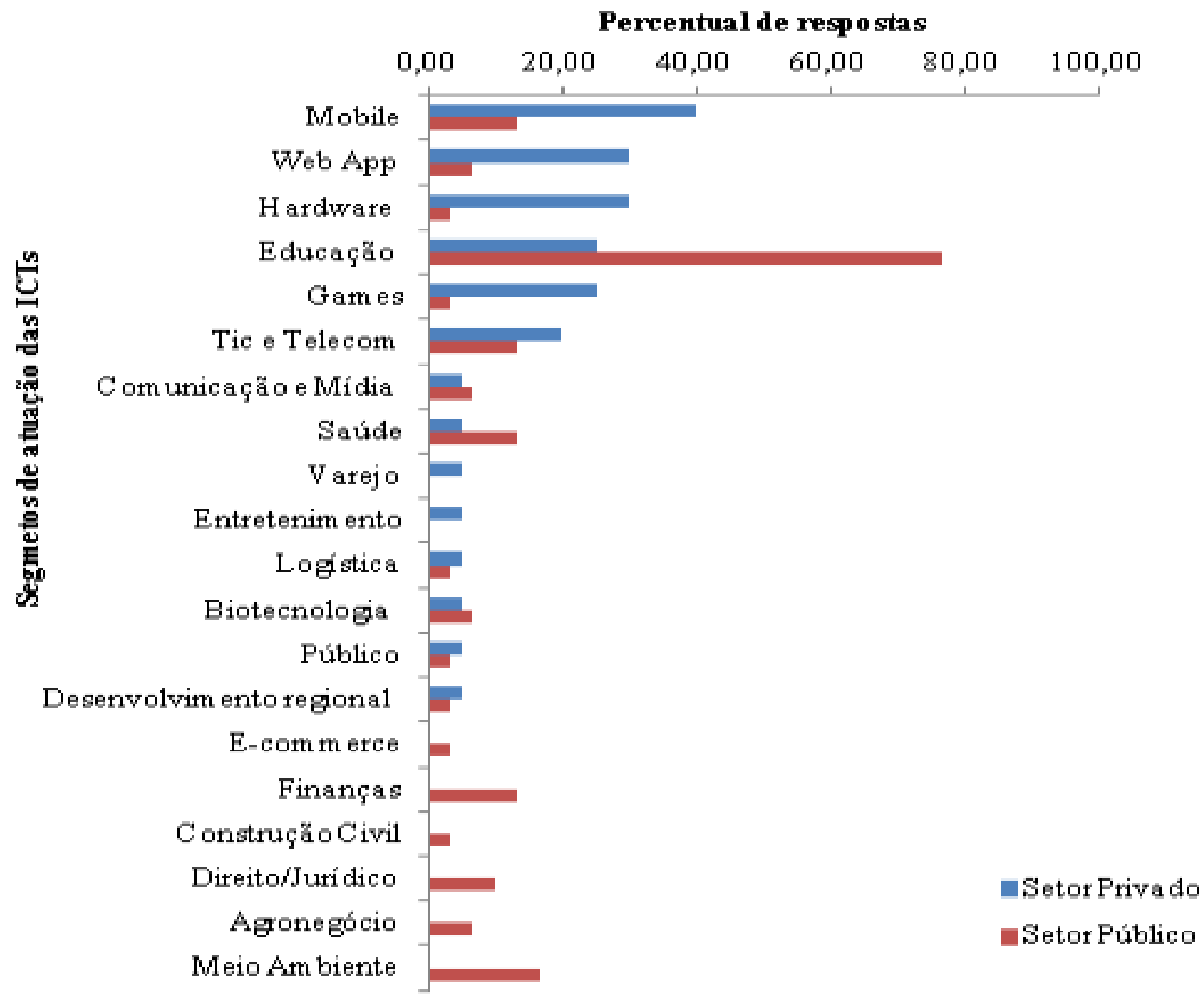

Fonte: Elaborado pelos autores deste artigo (2018) 
No Gráfico 6, são apresentados os percentuais da percepção dos respondentes sobre os investimentos de sua ICT em propriedade intelectual e sobre o incentivo aos colaboradores para que conheçam o tema, nesse caso, os maiores valores foram observados nas ICTs públicas $(66,7 \%)$ do que nas privadas $(45 \%)$. Ao somar os valores citados para a categoria de resposta de empresas que investem em propriedade intelectual, porém não incentivam os colaboradores a conhecerem sobre o tema, obteve-se um valor de $80 \%$ de incentivo para a propriedade intelectual em ICTs públicas e $60 \%$ nas ICTs privadas.

No setor privado, o percentual de respondentes que afirmaram que sua ICT não investe em propriedade intelectual e nem incentiva seu conhecimento foi de $20 \%$, que, junto ao percentual de pessoas que desconhecem o tema na instituição, chega a $40 \%$ no total.

No setor público e terceiro setor, esse percentual de respondentes sobre falta de investimentos na ICT foi de $6,70 \%$, que, somado aos $13,30 \%$ de pessoas que não sabem sobre o tema na ICT, atinge $20 \%$ dos respondentes desse segmento.

Gráfico 6 - As ICTs e a relação entre profissional e investimentos em propriedade intelectual

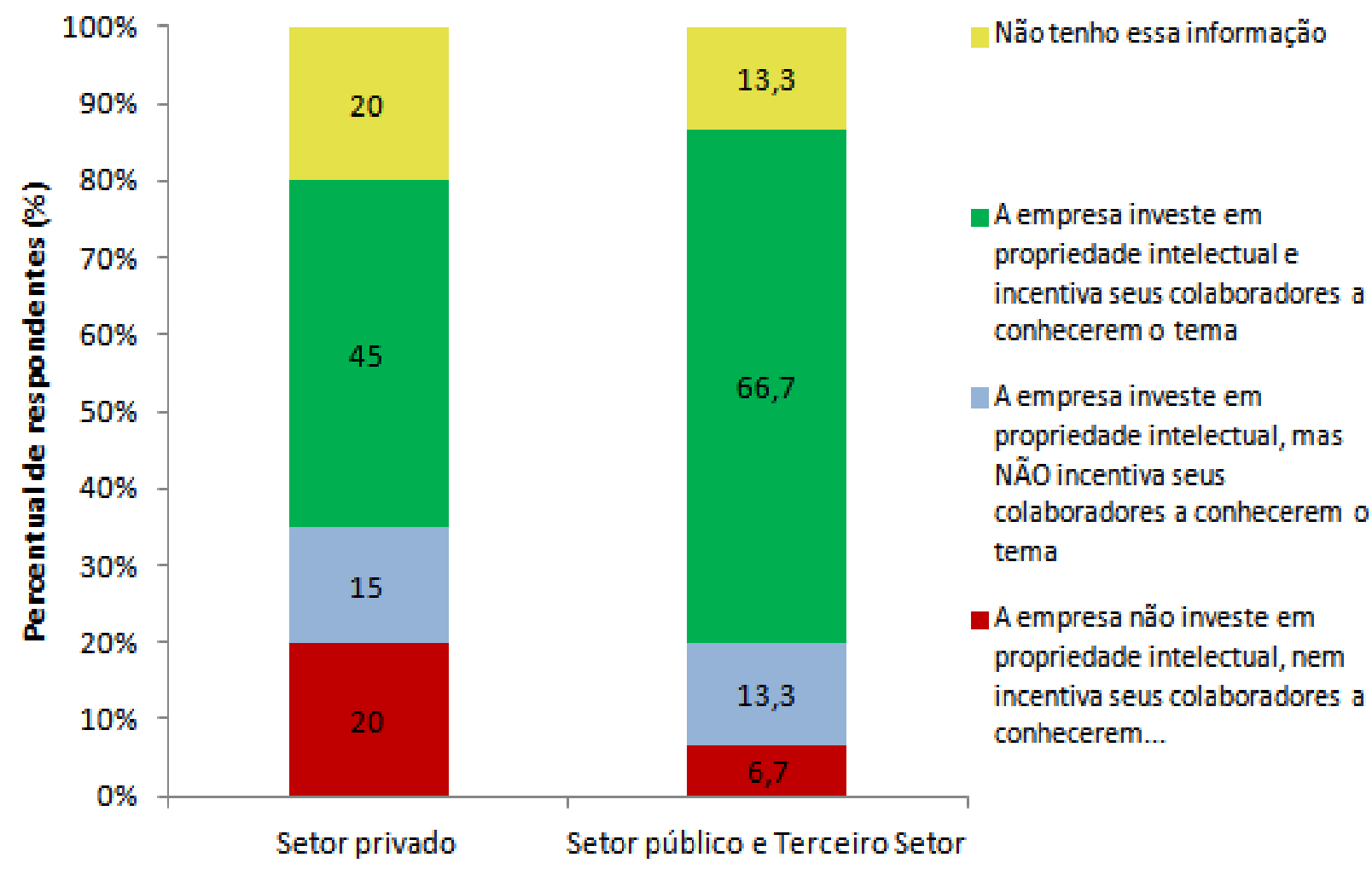

Fonte: Elaborado pelos autores deste artigo (2018)

Sobre as ICTs e os tipos de propriedades intelectuais com os quais as instituições se relacionam, os dados apresentados no Gráfico 7 mostram que existe diferença entre o setor privado e o setor público e terceiro setor. 
Gráfico 7 - ICTs dos profissionais respondentes e os tipos de propriedades intelectuais com os quais as instituições se relacionam, que aceita mais de uma resposta

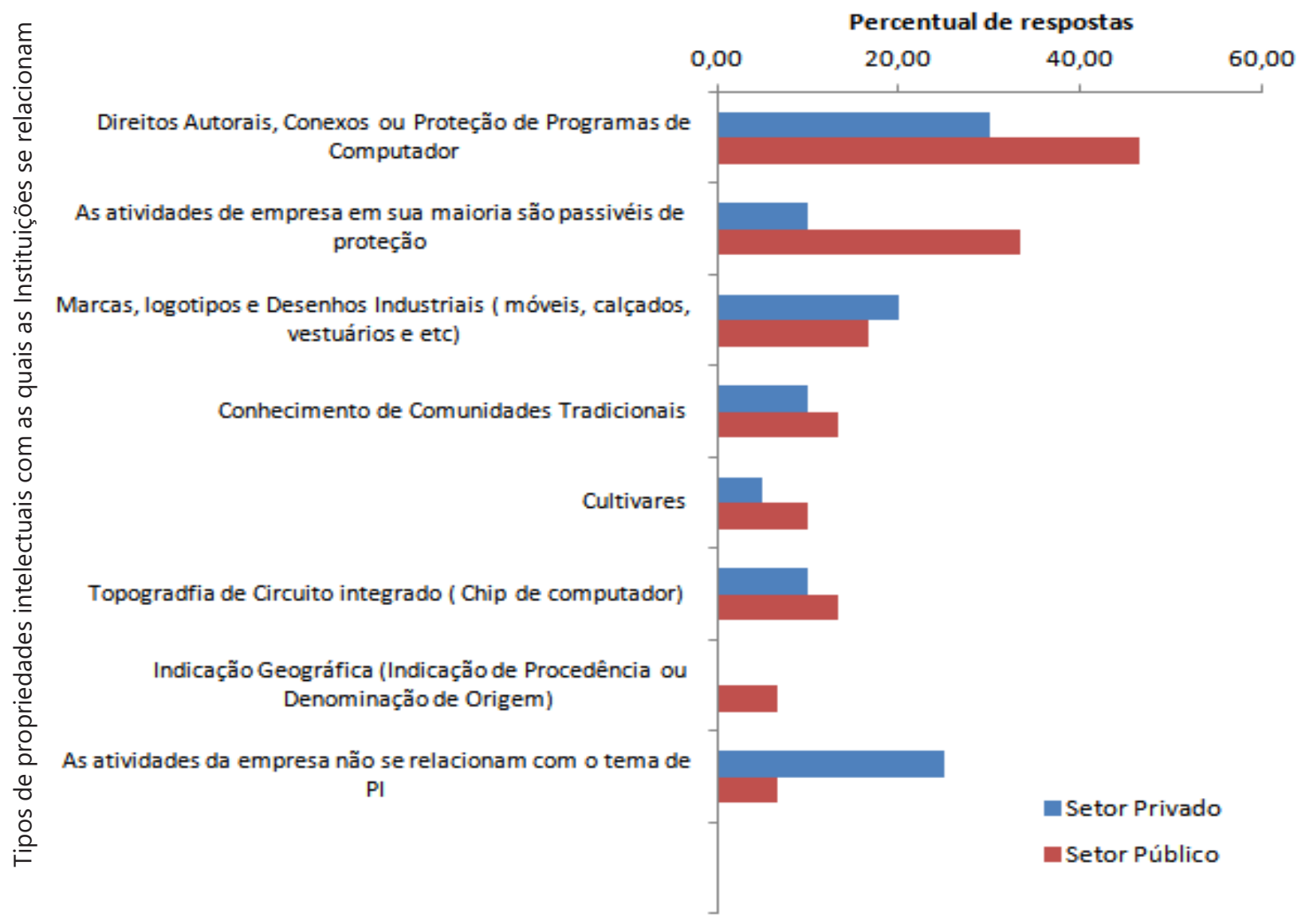

Fonte: Elaborado pelos autores deste artigo (2018)

No setor privado, percebe-se que a maior concentração de relação com propriedade intelectual está em direitos autorais, conexos ou proteção de programas de computador, representando $30 \%$ das respostas. Patentes de invenção e modelos de utilidades representam $20 \%$, assim como marcas e desenhos industriais. É importante destacar que $25 \%$ dos respondentes afirmaram que suas instituições não têm relação com o tema propriedade industrial.

No setor público e terceiro setor, percebe-se que as patentes de invenção e modelos industriais ganham força, pois $53.3 \%$ dos respondentes afirmam que sua instituição tem relação com esse tema. Em segundo lugar, com $46.7 \%$ vem a relação das instituições com Direitos autorais, conexos ou proteção de programas de computador.

Outro ponto pesquisado diz respeito à relação da empresa com a inovação, representado no Gráfico 8. 
Gráfico 8 - A relação da empresa com a inovação

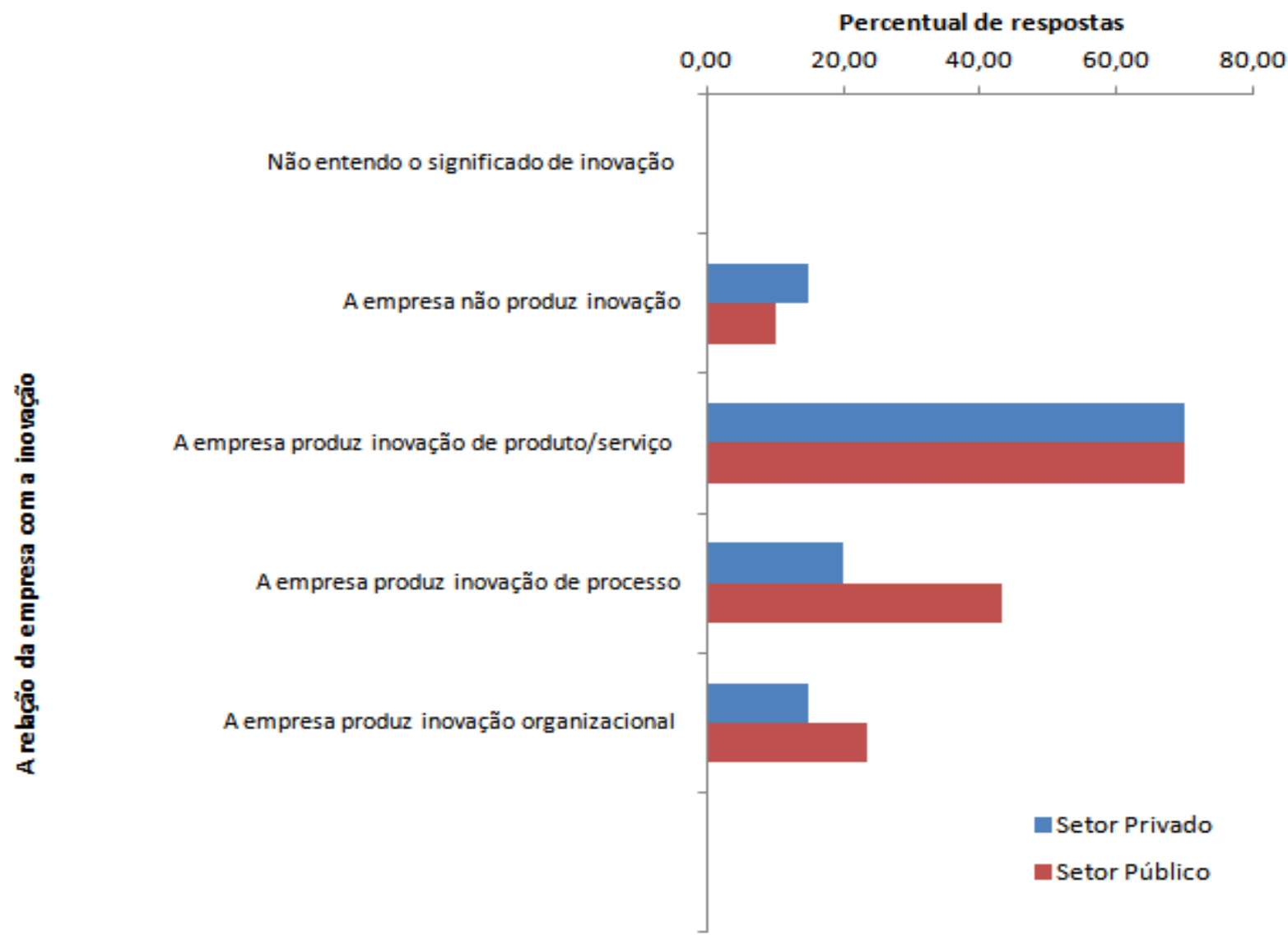

Fonte: Elaborado pelos autores deste artigo (2018)

Pode-se perceber que, no setor privado, a relação da inovação, de acordo com os respondentes, está presente na inovação de produtos e serviços, representando $70 \%$. Apenas $20 \%$ das respostas mostram que a gestão da inovação também se encontra nos processos.

No setor público e terceiro setor, também, se percebe que a maior parte da inovação diz respeito a produtos e serviços (70\%). Aqui difere a inovação em processos que representa um número maior de respondentes, pouco mais de $40 \%$. Um dado importante é que $23 \%$ dos respondentes afirmam que também existe inovação nos processos organizacionais.

\section{Considerações Finais}

O desenvolvimento desta pesquisa possibilitou identificar o cenário profissional e os conhecimentos acerca da propriedade intelectual, da transferência tecnológica e da inovação na cidade de Manaus. Embora a pesquisa seja de caráter opinativo, o cenário já pode ser interpretado em pontos relevantes, por exemplo, como os respondentes, profissionais de ICTs, encaram suas próprias relações e as de suas instituições com a temática da propriedade intelectual e da transferência tecnológica. Além disso, os resultados nos auxiliam a conhecer esse agente profissional interlocutor e suas interpretações sobre a problemática.

Em se tratando do perfil profissional, é possível perceber diferenças entre o setor público, o setor privado e o terceiro setor. Quando se analisou o perfil de escolaridade, percebeu-se 
que, no setor público, há um incentivo maior de educação especializada a nível de mestrado $e$ doutorado. Já o setor privado e terceiro setor são compostos, em sua maioria, de profissionais em nível técnico e de graduação.

A pesquisa apresenta também uma tendência superior nas ICTs do setor público e do terceiro setor de proximidade com a propriedade intelectual e com a transferência tecnológica do que o setor privado.

Como esperado, a área de maior aderência é o Setor de pesquisas, análise e ciência, seguido pelo de Criação, desenvolvimento e testes de produtos, processos e serviços (Design, Programação, Engenharia); porém também com participação considerável dos Setores administrativos, jurídicos e de Recursos Humanos; todavia, em uma expressividade menor que os demais.

Essa última consideração relacionada aos setores jurídicos e administrativos das ICTs públicas e do terceiro setor é relevante, principalmente pelo fato de a transferência tecnológica e a propriedade intelectual serem alvos de procedimentos jurídicos e de prospecção tecnológica administrativa, apresentando uma necessidade de maior exploração dessa área.

Percebeu-se maior aderência institucional na área de educação. Também se identifica aderência das áreas de softwares e hardwares, principalmente no desenvolvimento de mobiles, de aplicativos e de games.

A questão do investimento e do incentivo ao tema de propriedade intelectual e transferência tecnológica, pelo visto, parece obter maior relevância no setor público e terceiro setor, em comparação às opiniões dos respondentes do setor privado.

Por fim, pode-se concluir que, com base nas respostas desta pesquisa, tanto do setor privado quanto do setor público e terceiro setor, existe um alto conhecimento do tema propriedade intelectual, pois cerca de $70 \%$ dos que responderam à pesquisa afirmaram que conhecem a temática, embora os profissionais do Setor público são os que mostram que possuem maior relação do seu trabalho com a propriedade intelectual e a transferência de tecnologia.

Diante disso, pode-se inferir que existe oportunidades de transferência de tecnologia por parte das empresas e ICTs da cidade de Manaus. Para trabalhos futuros, é importante investigar se tais empresas e ICTs possuem processos ou políticas para incentivar inovação e executar formalmente a transferência de seus produtos/serviços para outros mercados.

\section{Referências}

BRASIL. Constituição Federal da República de 1988. Disponível em: http://www.planalto.gov.br/ ccivil_03/Constituicao/Constituicao.htm. Acesso em: 18 ago. 2019.

BRASIL. Decreto-Lei n. 288, de 28 de fevereiro de 1967. Disponível em: http://www.planalto. gov.br/ccivil_03/decreto-lei/Del0288.htm. Acesso em: 18 ago. 2019.

BRASIL. Lei n. 8.387, de 30 de dezembro de 1991. Disponível em: http://www.planalto.gov.br/ ccivil_03/LEIS/L8387.htm. Acesso em: 17 fev. 2019.

BRASIL. Emenda Constitucional n. 42, de 19 de dezembro de 2003. Disponível em: http:// www.planalto.gov.br/ccivil_03/Constituicao/Emendas/Emc/emc42.htm\#art3. Acesso em: 18 ago. 2019. 
BRASIL. Emenda Constitucional n. 83, de 5 de agosto de 2014. Disponível em: http://www. planalto.gov.br/ccivil_03/Constituicao/Emendas/Emc/emc83.htm. Acesso em: 18 ago. 2019.

CALEIRO, João Pedro. As 20 cidades com as maiores economias do Brasil. Revista Exame, on-line, ed. de abril de 2017. Disponível em: https://exame.abril.com.br/economia/as-20-cidades-com-asmaiores-economias-do-brasil/. Acesso em: 14 jan. 2019.

CONFORTO, E. C.; AMARAL, D. C.; SILVA, S. L. da. Roteiro para revisão bibliográfica sistemática: aplicação no desenvolvimento de produtos e gerenciamento de projetos. In: VIII CONGRESSO BRASILEIRO DE GESTÃO DE DESENVOLVIMENTO DE PRODUTO - CNGDP, 2011. Anais [...]. São Paulo, v. 8, n. 1.998, p. 1-12, 2011.

IBGE - INSTITUTO BRASILEIRO DE GEOGRAFIA E ESTATÍSTICA. Área Territorial Brasileira. [2017]. Disponível em: http://www.ibge.gov.br/home/geociencias/cartografia/default_territ_area.shtm. Acesso em: 5 jun. 2017.

IBGE - INSTITUTO BRASILEIRO DE GEOGRAFIA E ESTATÍSTICA. Área Territorial Brasileira. [2018]. Disponível em: https:/www.ibge.gov.br/estatisticas-novoportal/economicas/industria/9296pesquisa-industrial-mensal-producao-fisica-regional.html?edicao $=23556 \& \mathrm{t}=$ destaques. Acesso em: 14 jan. 2019.

INPI - INSTITUTO NACIONAL DA PROPRIEDADE INDUSTRIAL; CNI - CONFEDERAÇÃO NACIONAL DA INSDÚSTRIA. A caminho da inovação: proteção e negócios com bens de propriedade intelectual: guia para o empresário. Brasília, DF: IEL, 2010.

JORNAL EM TEMPO. Seminário aponta necessidade de nova estratégia para defesa da ZFM. [2019]. Disponível em: https://d.emtempo.com.br/economia/134410/seminario-aponta-necessidadede-nova-estrategia-para-defesa-da-zfm. Acesso em: 14 jan. 2019.

MINISTÉRIO DA CIÊNCIA, T. E. I. Política de Propriedade Intelectual das Instituições Científicas e Tecnológicas do Brasil. Relatório FORMICT 2013. Brasília, DF: Ministério da Ciência, 2014.

MINISTÉRIO DA CIÊNCIA, T. E. I. Política de Propriedade Intelectual das Instituições Científicas e Tecnológicas do Brasil. Relatório FORMICT 2014. Brasília, DF: Ministério da Ciência, 2015.

MINISTÉRIO DA CIÊNCIA, TECNOLOGIA, I. E. C. Política de Propriedade Intelectual das Instituições Científicas e Tecnológicas do Brasil. Relatório FORMICT 2015. Brasília, DF: Ministério da Ciência, Tecnologia, 2016.

MINISTÉRIO DA CIÊNCIA, TECNOLOGIA, I. E. C. Política de Propriedade Intelectual das Instituições Científicas e Tecnológicas do Brasil. Relatório FORMICT 2016. Brasília, DF: Ministério da Ciência, Tecnologia, 2017. p. 56.

OECD - ORGANIZATION FOR ECONOMIC CO-OPERATION AND DEVELOPMEN/ EUROSTAT. Oslo Manual 2018: Guidelines for Collecting, Reporting and Using Data on Innovation, 4th Edition, The Measurement of Scientific, Technological and Innovation Activities, OECD Publishing, Paris/Eurostat, Luxembourg. [2018]. Disponível em: https://doi.org/10.1787/9789264304604-en. Acesso em: 14 jan. 2019.

SAMPAIO, F. M.; MANCINI, M. C. Estudos de revisão sistemática: um guia para síntese criteriosa da evidência científica. Revista Brasileira de Fisioterapia, [S.I.], v. 11, n. 1, p. 83-89, 2007. 


\section{Sobre os Autores}

\section{Desirée Emelly Gomes Nascimento}

E-mail: desygomes23@gmail.com

MBA em gestão de projetos pela Universidade do Estado do Amazonas.

Endereço profissional: Centro de Pesquisa e Desenvolvimento UNA-SUS Amazônia, Av. Carvalho Leal, n. 1.777, Cachoeirinha, Manaus, AM. CEP: 69065-001.

\section{Acursio Ypiranga Benevides Junior}

E-mail: acursiobenevides@gmail.com

Mestre em Design pelo Programa de Pós-Graduação de Design da Universidade Federal do Amazonas.

Endereço profissional: Reitoria da Universidade do Estado do Amazonas, Av. Djalma Batista, n. 3.578, Flores, Manaus, AM. CEP: 69055-010.

\section{Daniela Azevedo da Silva}

E-mail: daniela.azevedo@sidia.com

Especialista em Gestão e Governança da Tecnologia da Informação.

Endereço profissional: Sidia Instituto de Tecnologia, Av. Darcy Vargas, n. 654, Parque Dez de Novembro, Manaus, AM. CEP: 69055-035.

\section{Érika Santos Gomes}

E-mail: erika.gomes@ifam.edu.br

Especialista em Gerenciamento de Projetos pela Universidade do Norte.

Endereço profissional: IFAM, Av. Onça Pintada, s/n, Galo da Serra, Presidente Figueiredo, AM. CEP: 69735-000.

\section{Rosa Maria Nascimento dos Santos}

E-mail: rmsantos@uea.edu.br

Doutora em Meteorologia pelo Instituto Nacional de Pesquisas Espaciais.

Endereço profissional: Escola Superior de Tecnologia - EST/UEA, Av. Darcy Vargas, n. 1.200, Parque 10 de Novembro, Manaus, AM. CEP: 69050-020.

\section{Raimundo Correa de Oliveira}

E-mail: rcoliveira@uea.edu.br

Doutor em Engenharia Elétrica.

Endereço profissional: Escola Superior de Tecnologia - EST/UEA, Av. Darcy Vargas, n. 1.200, Parque 10 de Novembro, Manaus, AM. CEP: 69050-020. 